\title{
IN GOOD COMPANY
}

\section{Academic life isn't for everyone. Here we profile scientists who have made the switch from academia to industry, all motivated by a desire to see their discoveries translated into real-world solutions.}

BY ELIE DOLGIN

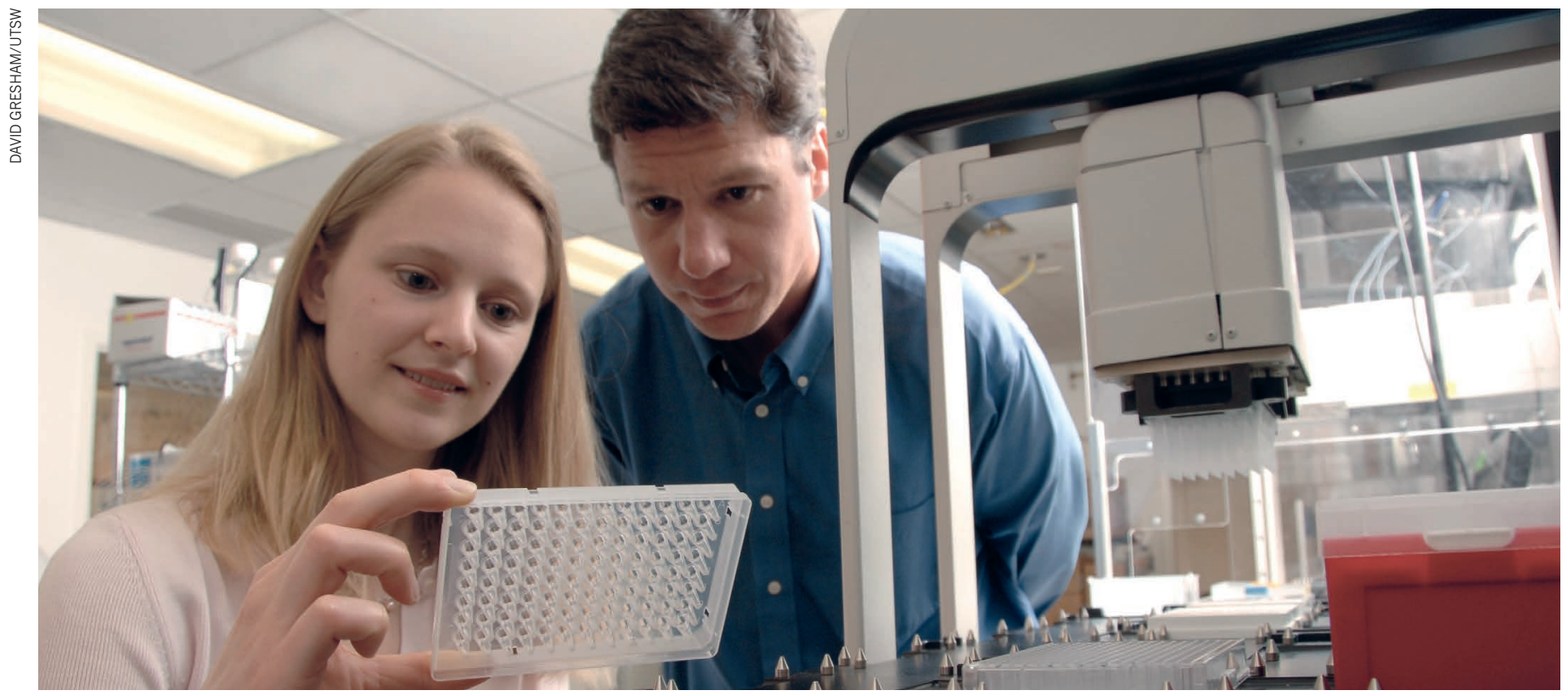

Michael White works with postdoctoral researcher, Angelique Whitehurst, in his former role at the University of Texas Southwestern Medical Center.

\section{MICHAEL WHITE}

\section{Golden ticket}

In 2015, Michael White won a prestigious Outstanding Investigator Award from the United States National Cancer Institute worth US\$6.5 million. But, after 20 years studying the basics of cancer cell signalling at the University of Texas Southwestern Medical Center in Dallas, White realized he didn't want to keep doing more of the same.

So, he handed back the grant money and joined Pfizer last year to lead the pharmaceutical company's tumour cell biology division in La Jolla, California. "I walked away from Willy Wonka's chocolate factory is what I did," White says. Some might say he swapped one golden ticket for another.

Like most early- to mid-career academics who leave university appointments to run industry labs, White was drawn in part by the higher salary on offer at Pfizer and the steady research budgets that don't require endless grant writing. But, the main impetus for him and others who have made a similar career switch was a desire to see the fruits of their scientific labour make a difference in people's lives. "It's an opportunity to make drugs instead of papers," White says. Pfizer is among the top five corporate institutions in the Nature Index, accruing a weighted fractional count (WFC) of 110 over the past five years.

\section{ZAVEN KAPRIELIAN}

\section{Personal discovery}

The move to industry can be deeply personal. Zaven Kaprielian had made a career studying the early development of neurons in mice, worms and other model laboratory organisms. He had no experience with drug discovery, and no prior collaborations with pharmaceutical

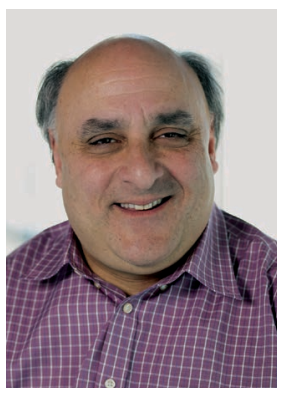
companies. But after his father developed dementia and moved into an assistedliving facility with many other patients afflicted with the same condition, Kaprielian became acutely aware of the impact of neurodegeneration.
"It was shocking to me," he says. "Here I am, a neuroscientist, thinking I understand the disease, and I didn't realize how tragic it was." After 18 years running an academic lab at the Albert Einstein College of Medicine in the Bronx, New York, in 2013 Kaprielian joined the biopharmaceutical company, Amgen, as a director of neuroscience at its research facilities in Cambridge, Massachusetts. He now leads Amgen's drug discovery programme for two neurodegenerative diseases, Parkinson's and amyotrophic lateral sclerosis.

Former academics acknowledge there are drawbacks to working in the corporate world. Research priorities are often dictated by senior management, which can thwart intellectual freedom, and much more time is spent running from meeting to meeting. But what academic émigrés miss most from their former lives are the interactions with graduate students. "There's a special mentoring that comes with that arrangement," says Kaprielian.

Most large research and technology companies, however, do have postdoctoral programmes that offer opportunities to continue training the next generation of scientists. Ajamete Kaykas, for example, has filled his lab at the Novartis Institutes for BioMedical Research 


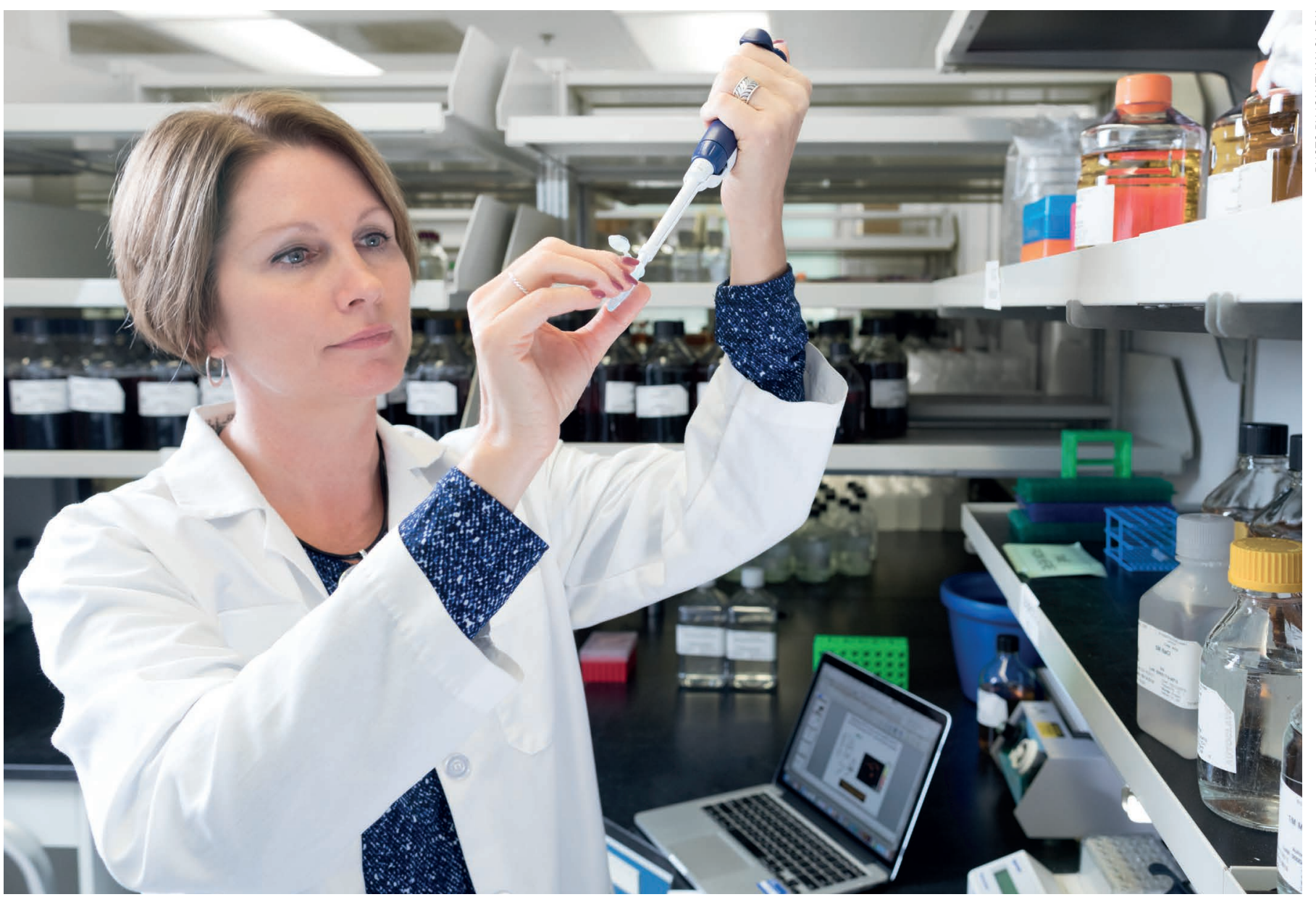

Immunologist, Shannon Turley, left academia for a role at Genentech developing new cancer therapies, one of which will soon be tested in patients.

in Cambridge, Massachusetts, with postdocs who are developing stem-cell-based models of brain development for drug target discovery. He also maintains active collaborations with university partners and regularly attends scientific meetings, just as he once did in his job at the non-profit Allen Institute for Brain Science in Seattle, Washington.

Those kinds of scholarly activities are "a big part of job satisfaction," Kaykas says. "It does keep a little bit of the academic element, which I think is important."

\section{SHANNON TURLEY}

\section{Closer to care}

For Shannon Turley, the move to industry started with a request for a reference. After 10 years running an immunology lab at the Dana-Farber Cancer Institute in Boston, Massachusetts, Turley was considering changing universities and asked her former $\mathrm{PhD}$ advisor, Ira Mellman, for a letter of recommendation. Mellman, who had left Yale University in 2007 to lead cancer drug discovery research efforts at the biotech firm Genentech, encouraged Turley to consider working for him instead.

At first, Turley hesitated. "I'm an academic at heart. I didn't see myself in industry at all," she says. But after visiting Genentech's laboratories in South San Francisco, California, she had a moment of clarity: by moving to Genentech, she would be able to continue her fundamental research into the role of surrounding connective tissue in anti-tumour immune responses, while helping to transform discoveries into therapies for patients.

\section{"I'M AN ACADEMIC AT HEART. I DIDN'T SEE MYSELLF
IN INDUSTRY AT ALL."}

In 2014, she joined the company, a subsidiary of Roche that makes up more than $80 \%$ of the Swiss multinational's share of authorship in the Nature Index. At Genentech, Turley leads a team of around two dozen researchers working on several early-stage programmes for potential new medicines, one of which could begin testing in patients within the next few years.

\section{SIYUAN LU}

\section{Rain and shine}

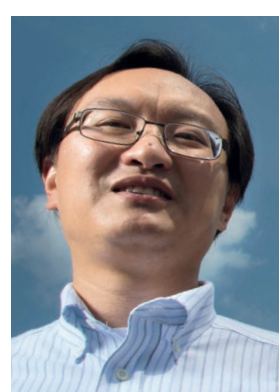

"You can pursue a bigger vision in industry," notes Siyuan Lu, a physicist who, in 2012, left his position as an assistant research professor at the University of Southern California in Los Angeles to join IBM, the top corporation in the index 2012-2016, with a WFC of 267. As head of the Data Intensive Physical Analytics research group at IBM's Thomas J. Watson Research Center in Yorktown Heights, New York, Lu is now in charge of, among other things, the company's geospatial platform, used by financial institutions and other clients for weather prediction and agricultural forecasting.

"I get to see my work come alive," says Lu, who contrasts his current position with his earlier academic setting, where his work on nanostructured vision-restoring implants was never tested in animal models, let alone in patients. 